\title{
Assessment of Offshore Piping Composite Repair Technology for Life Extension Program Case in Pertamina Hulu Energy West Madura Offshore
}

\author{
Muhamad Arifin ${ }^{1,2} *$, Arif Cahyono ${ }^{2},{\text { Idam } \text { Putra }^{2} \text {, and Badrul Munir }}^{1}$, \\ ${ }^{1}$ Department of Metallurgical and Materials Engineering, Faculty of Engineering, Universitas Indonesia, Kampus UI Depok, Indonesia \\ ${ }^{2}$ Pertamina Hulu Energi West Madura Offshore
}

\begin{abstract}
The pipe work repair method such as clamps and pipe connector as the use of metallic repair component have been used for maintenance and repair application in oil and gas industry and cover the most common types of defect to pressurize system like internal and external corrosion and also cover situations where the damage is severe. On the other hand with a process safety precausion and production concern, in oil and gas facility the use of metallic repair is very challenging and most of the time will come as last option scenario. Composite repair which are now increasing in application to pipe repair situations may come as a solution. This paper provides assessment of offshore piping composite repair for life extension program of pressure system in West Madura Offshore. Assessment come to a conclusion that the composite repair at field PHE WMO which operate on envelop of $700 \mathrm{psi}$ and temperature range of $20 \mathrm{oC}-80 \mathrm{oC}$ are still in good condition and retain the integrity of the asset, from where then the repair is considered to extent its lifetime.
\end{abstract}

\section{Introduction}

Pertamina Hulu Energy West Madura Offshore (PHE WMO) is one of local production sharing contract Company that manages oil and gas resources at West Madura area, located at about $70 \mathrm{~km}$ off the coast Gresik East Java in Fig.1. PHE WMO strives to commit of performing safe operations and improving production efficiency. Asset Integrity Managment System (AIMS) is implemented at PHE WMO with the main objective to ensure the process safety and production reliability of facilities and operations through their remaining producing lives.

It is also intended to standardize a common approach to integrity management of facilities, assure riskbased processes are applied. This process is developed into integrity management cycle: Plan, Do, Check, Action (PDCA) cycle as basis to establish asset integrity program. Currently PHE WMO operates 16 active fixed offshore platforms with steel jacket template type with various numbers of legs. Common platform type used at platform is braced-monopod (especially at wellhead platform).

With the asset contains of number of offshore facilities, it requires the strategy that cover the systematic program in inspection, maintenance, and repair which can assure the fitness of service ability of the assets.

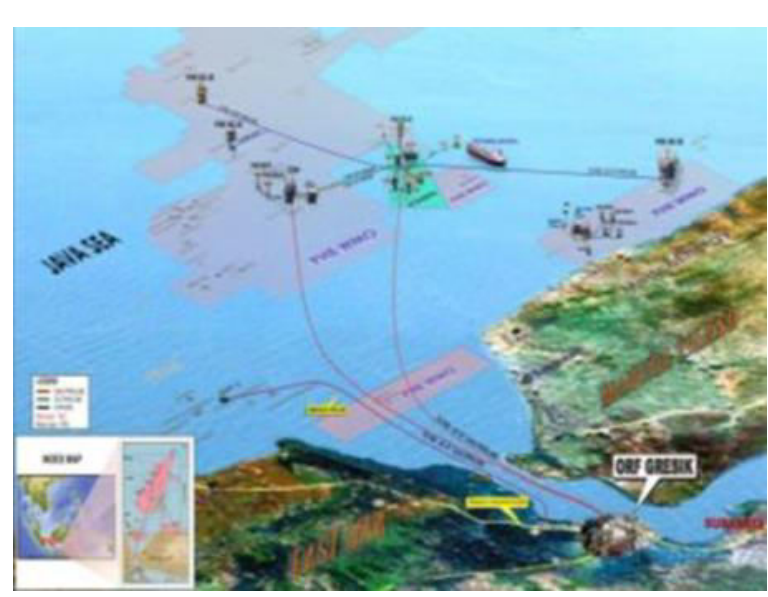

Fig 1. Lay Out of PHE WMO Field

The scope of PHE WMO AIMS applies to all production and related facilities across the field, as summarize in fig 1, more specifically these include, topside pressure system, pipelines, offshore structure, and floating system including SPM, PLEM, Subsea/floating hoses. 


\section{Pressure System Integrity Management Methodology}

To successfully achieve the commitment and maintain the asset for full lifecycle, Pressure System Integrity Managemen System (PSIMS) is focused on top side mechanical static equipment area which cover the following item:

- Pipeline

- Pipe and Pipework system for process fluids, hydrocarbon, fire water

- Pressure vessel with design construction refer to ASME BPVC section VIII

- Tank with which constructed refer to ASME BPVC section VIII

Depend on the defect, leak and operation condition repair may undertake with the following approach: In kind replacemen (Hot Repair), temporary repair until the replacement can be done, and permanent repair whenever replacement is not possible [4,5]. To respond a quick and reliable way to overcome the piping and pressure vessel integrity in case of leak occurences and critical defect or anomaly presence in the field top side pressure system equipment, effective and sistematic way need to be established within the Company by ensuring that all defined life repairs carried out to in service hydrocarbon and safety critical system are risk assessed and carried out in a safe, engineered and controlled manner, choosing an apropriate repair technique for a specific type of defect or combination of defects in pressure system, and ensuring repairs are formally record and procedures are in place to ensure that an auditable repair register is maintained.

\section{Review the Use of Composite Repair at Field PHE WMO}

This composite materials used for repair review is intended to present an overview of the work that is currently being practiced within PHE WMO offshore field on piping and pipe repairs using composite materials. The objective of the technical work carried out is to establish a framework for installation, operation, maintenance and longevity of the repair.

\subsection{Repair Philosophy}

The overall philosophy of repair in PHE WMO is "performance based", which is no prescription in terms of materials (either fibres or resin) nor minimum strengths is provided, the supplier who perform the repair demonstrates the performance of the composite repair system through testing comply to standards specify for oil and gas insdustry. The testing performed should be able to replicate those procedures used in the offshore field.

\subsection{Permanent and Temporary Repair Terminology}

ASME/ANSI B31.3 describe the rules for the design, fabrication, inspection and testing of new pipe and piping systems, they do not address the fact that these systems may degrade during in service and afterward require repair $[6,7,8]$ Offshore technology Report from AEA recommend that repair longevity within the field are temporary for limited period up to 2 years and considered permanent for remaining lifetime of economic the pipe and piping system [6]. On the otherhand from the two different standards repair lifetime is considered not to use the term "temporary" or "permanent". The lifetime of the repair shall be defined by the end user on which refer to the repair design based, the maximum design life within these standard is 20 years, where then at the end of design life the end user must either to replace the repaired pipe \& piping or evaluate the repair and possible to extend its lifetime [9.10].

Insitu repair at PHE WMO field using composite considers pressure system at main platform and processing unit like PPP, CPP and ORF layout shown in Fig.1, which include utility fluids, main gas line (MGL) and main oil line (MOL). The operating envelope up to $700 \mathrm{psi}$ and continuous temperature from ambient to $80{ }^{\circ} \mathrm{C}$.

\subsection{Procedure Application}

Supplier of composite repair material provide specific guidance that describe the design and application of their repair scenario. For bandage type material there should be datasheets containing detail such as number of layers which should be applied for specific repair situation. Information expressed as a function of pressure, temperature, diameter etc, shall be typical. For low duties application the governing parameter will not be applied load, but minimum thichkness. For example, in PHE WMO it commons to apply 3 layers at minimum to properly support the overlaps and edges and that flaws (e.g. damage to manufacture reinforcement, tears etc.) caused by the overwrapping operation are adequately covered. For higher duties application or repairs that are undertaken by a well known contractor, the design must be supported by calculations done by the material supplier. These calculations may require verification by a third party.

\subsection{Assement of Composite Repair Application in PHE WMO Field}

For years, at PHE WMO the most common practice for repair a corroded pipe and piping is to dismantle the pipe or replacing only a localized section and then replacing it with a new one. Alternatively, the repair can be done by installing steel sleeve or clamp. These conventional repair techniques combine external steel sleeves that are welded or bolted to the the pipes and piping as shown in Fig.2. 
PHE WMO in 2013 started to use alternative approach of using composite based materials that have became a popular alternative approach of repair system for damaged steel pipe. Repairs made by composite materials offer numerous advantages over conventional, welded repairs, reduce overall repair cost and prevent from prolong shutdown.

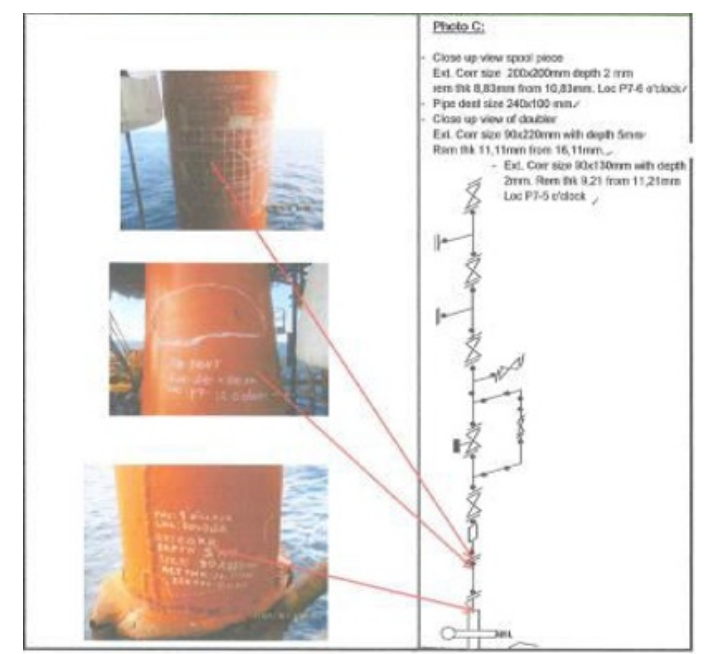

Fig.2 Common Convetional Repair for years at CPP, PHE WMO

It came to attention that composite repair technology's safety, convenience and constancy, no need of welding job, and the advantages such as designability and durability, it has been widely applied in the repair for steel in pressure sytem. Furthermore at PHE WMO, the acceptance of composite based materials as an alternative to traditional repair materials is indicated through current assessment of the lifetime of the repair status done in 2013, this would recommend that the repair shall be replaced with new one or extend lifetime furthermore. This align with the development of codes and standards, including but not limited to ASME PCC-2 [9] and ISO/TS 24817 [10]. Both standards notice composites as a legitimate repair material.

PHE WMO develop an assurance proses by performing surface preparation and a mock up test using a hydrotest approach of ASTM B31.3 [11] with criteria "No Leak Indication", by only meet this criteria one product can be recommended to be installed at Field for repair pipework.

\subsection{Inspection of Composite Repair}

- Visual inspection of repair for external defect, indication delamination will be initiated at the edge of repair

- Visual inspection for for internal defect like edge delamination and also check for discolouration

- Radiography or Electromagnetic e.g. SLOFEC, PEC, for inspection of the steel pipe underneath the repair

- Inspection the interface (development trials on-going) by advance inspection using Eddy Current
Base on the last inspection carried out in 2018, that all the composite repair done at offshore PHE WMO in CPP, PPP and ORF are still in good condition, no defect and anomaly found on the composite, showed in table 1. Result showed that 18 out of 22 composite repair are reported retain the integrity and still in good condition, the rest of 4 repair were replaced with metal spool during Turn Arround shutdown in 2017. Special case on the repair due to defect on external corrosion, after several years underneath the composite there is no indication the occurence of further deterioration.

Table 1. Inspection Result of the Composite Repair at Site

\begin{tabular}{|c|c|c|c|c|c|}
\hline No & Location & $\begin{array}{c}\text { Asset } \\
\text { Type }\end{array}$ & Asset Number & $\begin{array}{c}\text { Year } \\
\text { Installed }\end{array}$ & $\begin{array}{c}\text { Inspection April } \\
\mathbf{2 0 1 8}\end{array}$ \\
\hline 1 & CW & Riser & Inc from DW 12" & 2013 & Good condition \\
\hline 2 & BW & Riser & Out frm BW 6" & 2013 & Good condition \\
\hline 3 & ORF & Riser & Out to PJB 10" & 2013 & Good condition \\
\hline 4 & AW & Riser & Inc from BW 12 & 2013 & Good condition \\
\hline 5 & AW & Riser & Out to CPP 14" & 2013 & Good condition \\
\hline 6 & CPP & Riser & Inc from AW 14" & 2013 & Good condition \\
\hline 7 & ORF & Riser & Inc from CPP 14" & 2013 & Good condition \\
\hline 8 & AW & Piping & PL-9800-D-3" & 2015 & Good condition \\
\hline 9 & AW & Piping & PL-3009-D-6" & 2015 & Good condition \\
\hline 10 & 38 A & Vessel & Gas Filter Coalescer & 2015 & Good condition \\
\hline 11 & CPP & Piping & Al-101-N-2" & 2015 & Good condition \\
\hline 12 & CPP & Piping & Al-604-N-3" & 2015 & Good condition \\
\hline 13 & CPP & Piping & D-115-A-1" & 2016 & Good condition \\
\hline 14 & CPP & Vessel & V-108A & 2016 & Good condition \\
\hline 15 & CPP & Vessel & V-108B & 2016 & Good condition \\
\hline 16 & AW & PP & VT-4225-A-2" & 2016 & 2017 was replaced \\
\hline 17 & AW & PP & VT-9804-A-2" & 2016 & 2017 was replaced \\
\hline 18 & AW & PP & OW-5080-D-2" & 2016 & 2017 was replaced \\
\hline 19 & AW & PP & Al-9801-T-1" & 2016 & 2017 was replaced \\
\hline 20 & PHE-38A & PP & VT-3042-A-1/2" & 2016 & 2017 was replaced \\
\hline 21 & ORF & Tank & T-201 B & 2016 & Good condition \\
\hline 22 & ORF & Tank & T-201 B & 2017 & Good condition \\
\hline
\end{tabular}
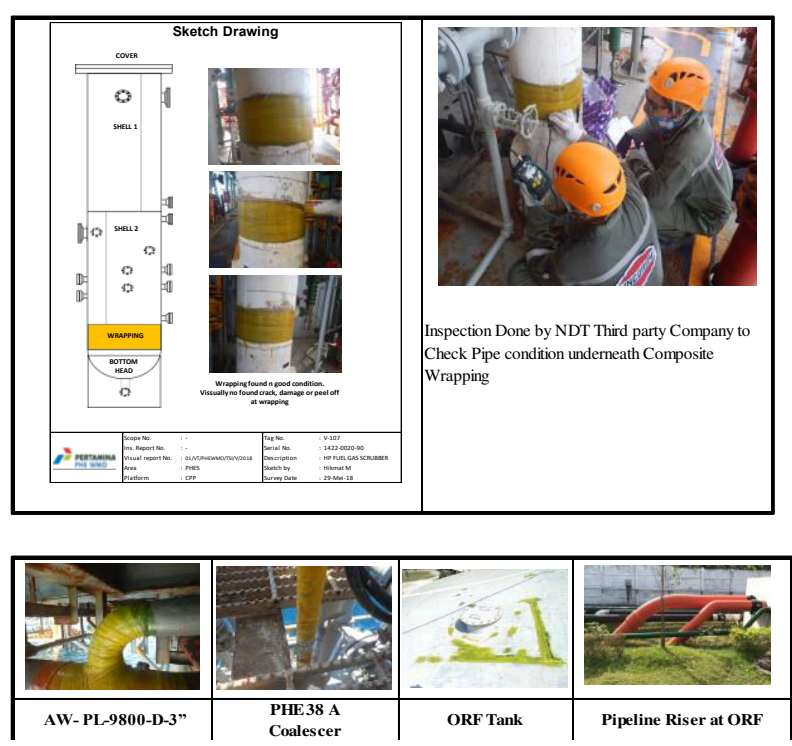

Fig. 3. Inspection Activity and Picture of Composite Repair Visual

Figure 3 showed inspection activity using eddy current and condiion of composite after being installed for about 5 years. 


\section{Conclusion}

Composite repair at PHE WMO is considered to be effective due to its simplicity during instalation, and ability to prevent prolong plant shutdown which reduce overall repair cost. Safe and Reliable operation can also be promoted because of composite repair technology's safety during construction, convenience and constancy, no need of welding job, and its advantages such as easy to design and high durability.

Base on the assessment of composite repair at PHE WMO with the operating envelop of pressure up to $700 \mathrm{psi}$ and the temperature range of $25^{\circ} \mathrm{C}$ to $80^{\circ} \mathrm{C}$, the repair status is still good and able to retain the integrity by then the end user has decided to extend their lifetime for another 2 years. It will definitely need the management of the integrity and PHE WMO will ensure that it will be implemented through the Asset Integrity Management System which is already establish at the company.

\section{Reference}

1. PHEWMO-PHEWMO-G-PRC-0001.Rev.1 (PHE WMO AIM Policy \& Standard, 2017)

2. PHEWMO-PHEWMO-O-MAN-0001.Rev.2 (Asset integrity Management System, 2017)

3. PHEWMO-PHEWMO-M-PRC-0001.Rev.0 Surface Facility Integrity Management System (2017)

4. PHEWMO-PHEWMO-M-PRC-0002-rev.0 (Repair Procedure for Piping, 2017)

5. PHEWMO-PHEWMO-M-PRC-0007-rev.0 (Repair Procedure for Pressure Vessel, 2017)

6. OFFSHORE TECHNOLOGY REPORT 2001/038, Temporary/permanent pipe repair-Guidelines, , AEA Technology Consulting E1 Culham Abingdon Oxfordshire OX14 3ED United Kingdom

7. ASME B31.4. Liquid transportation system for hydrocarbons, liquid petroleum gas, anhydrous ammonia and alcohols. New York: American Society of Mechanical Engineers; (2003)

8. ASME B31.8. Gas transmission and distribution piping systems. New York: American Society of Mechanical Engineers; (2003).

9. ASME PCC-2 Repair of pressure equipment and piping. 2011, New York, USA.

10. ISO/TS 24817 Petroleum, petrochemical and natural gas industries - composite repairs of pipework qualification and design, installation, testing and inspection., Switzerland (2006)

11. ASME B31.3 Process Piping, New York: American Society of Mechanical Engineers (2003) 